\title{
O Uso da "Game Câmera" como Ferramenta para Monitoramento da Visitação nas Furnas Gêmeas - Parque Nacional dos Campos Gerais - PR
}

\author{
The Use of "Camera Game" as a Tool for Visiting Monitoring in the Furnas Gêmeas - \\ Campos Gerais National Park - PR
}

\begin{abstract}
El Uso del "Game Cámara"como Herramienta para Monitoreo de la Visitación en las Furnas Gêmeas - Parque Nacional dos Campos Gerais - PR
\end{abstract}

\author{
Jéssica Camila Garcia Ribeiro ${ }^{1}$ \\ Jasmine Cardozo Moreira ${ }^{2}$
}

\begin{abstract}
RESUMO: O Parque Nacional dos Campos Gerais (PNCG) está localizado nos municípios de Ponta Grossa, Castro e Carambeí na região Centro-Leste do Paraná. Entre os locais que apresentam visitação no interior do parque, encontra-se o atrativo Furnas Gêmeas, local caracterizado pela feição de relevo cárstico. Até abril de 2018 o acesso a este atrativo era livre, não existindo controle ou manejo nas visitações, deste modo foi realizado o monitoramento de visitantes na entrada do atrativo. Utilizou-se como metodologia a coleta de imagens com câmera, que incluíram o reconhecimento da área, testes de fixação, tempo de coleta e intervalo de captura, além da pesquisa bibliográfica e documental. $\mathrm{O}$ artigo tem por objetivo apresentar o total de visitas, horários e dias da semana em que foi registrado maior fluxo. No total, a coleta foi realizada em seis meses (entre novembro de $2017 \mathrm{e}$ abril de 2018). Com base nas análises, pode-se compreender que uma das atividades realizadas é a contemplação da paisagem no pôr do sol, visto que o atrativo não oferece nenhuma estrutura no local além de sua própria beleza natural. Os dados apresentados podem servir como auxílio para um futuro plano de uso público.
\end{abstract}

PALAVRAS-CHAVE: Parque Nacional dos Campos Gerais. Furnas Gêmeas. Visitantes. Monitoramento. Game Câmera.

ABSTRACT: Campos Gerais National Park (PNCG) is located in the municipalities of Ponta Grossa, Castro and Carambeí in the Center-East region of Paraná. Among the places that have visitation inside the park is the attractive Furnas Gêmeas, a place characterized by the karst relief feature. Until April 2018, access to this attraction was free, with no control or management in the visitations. This way, visitors were monitored at the entrance of the attraction. The methodology used was the collection of camera images, which included area recognition, fixation tests, collection time and capture interval, as well as bibliographic and documentary research. The article aims to present the total visits, times and days of the week in which the highest flow was recorded. In total, the collection

\footnotetext{
${ }^{1}$ Universidade Estadual de Ponta Grossa. Rua Carlos de Carvalho, 159, Uvaranas, Cep 84032-090, Ponta Grossa, PR - Brasil. jessicacgribeiro@gmail.com.

2 Universidade Estadual de Ponta Grossa, Departamento de Turismo. Pça Santos Andrade, s/n, Centro, Cep 84100-000, Ponta Grossa, PR - Brasil. jasminecardozo@gmail.com.
} 
was performed in six months (between November 2017 and April 2018). Based on the analysis, we can understand that one of the activities performed is the contemplation of the landscape at sunset, since the attraction offers no structure in the place other than its own natural beauty. The data presented may serve as a contribution to a future plan for public use.

KEYWORDS: Campos Gerais National Park. Furnas Gêmeas. Visitors. Monitoring. Camera.

RESUMEN: El Parque Nacional Campos Gerais (PNCG) se encuentra en los municipios de Ponta Grossa, Castro y Carambeí, en la región centro-este de Paraná. Entre los lugares que tienen visitas dentro del parque se encuentra el atractivo Furnas Gêmeas, un lugar caracterizado por la característica de relieve kárstico. Hasta abril de 2018, el acceso a esta atracción era gratuito, sin control ni gestión en las visitas, por lo tanto, los visitantes fueron monitoreados en la entrada de la atracción. La metodología utilizada fue la colección de imágenes con una cámara, que incluyó reconocimiento de área, pruebas de fijación, tiempo de colección e intervalo de captura, así como investigación bibliográfica y documental. El artículo tiene como objetivo presentar el total de visitas, horarios y días de la semana en que se registró el flujo más alto. En total, la colección se realizó en seis meses (entre noviembre de 2017 y abril de 2018). Según el análisis, se puede entender que una de las actividades realizadas es la contemplación del paisaje al atardecer, ya que la atracción no ofrece una estructura en el lugar que no sea su propia belleza natural. Los datos presentados pueden servir como ayuda para un plan futuro para uso público.

PALABRAS-ClAVE: Parque Nacional dos Campos Gerais. Furnas Gêmeas. Visitantes. Monitoreo. Cámara.

\section{INTRODUÇÃO}

O Parque Nacional dos Campos Gerais - PNCG - foi legalmente criado através do Decreto Lei s/no em 23 de março de 2006 (BRASIL, 2006), com o propósito de preservar os ecossistemas naturais de Campos Limpos (gramíneas) secos com afloramentos rochosos e úmidos, também a Floresta Ombrófila Mista Aluvial/Matas de galerias, Capões isolados de Floresta Ombrófila Mista Montana (araucária angustifólia, predominantemente em clima temperado úmido de altitude) e fragmentos de Cerrado (savana).

O Parque Nacional dos Campos Gerais está localizado nas cidades de Ponta Grossa, Castro e Carambeí, sendo a maior porção no município de Ponta Grossa. O parque ainda não possui plano de manejo e a gestão é feita pelo Instituto Chico Mendes de Conservação da Biodiversidade (ICMBio). Sua regularização fundiária está no início, a Nota Técnica no 001 fez menção a 12 processos de desapropriação já iniciados administrativamente (PARANÁ, 2019).

Este artigo trata do monitoramento do número de visitantes no atrativo Furnas Gêmeas, localizado dentro do PNCG, no Paraná, usando como ferramenta a Game Câmera. A metodologia é baseada na coleta de imagens, e os registros foram feitos em diferentes intervalos de tempo. Durante seis meses as imagens foram analisadas no 
software Game Finder. A partir das imagens, foi realizada a contagem dos visitantes que entravam na trilha, no período de 09 de novembro de 2017 a 30 de abril de 2018, identificando em quais horários, dias da semana e mês as visitações aconteceram com mais frequência.

A ausência do monitoramento do número de visitantes pode comprometer a resiliência dos ecossistemas. Assim, o artigo apresenta a base teórica sobre unidades de conservação, monitoramento, caracterização da área de estudo (antiga trilha do atrativo Furnas Gêmeas, localização e infraestrutura da nova trilha), o número total de visitantes em cada mês, o total de visitas por hora referente aos seis meses de coleta e a contagem manual após o encerramento da coleta com a câmera.

Como forma de orientar a leitura, o presente trabalho trata no primeiro momento, da contextualização da Unidade de Conservação (UC), seguido da fundamentação teórica, discorrendo como se caracteriza uma unidade de conservação, assim como os conceitos de uso público e monitoramento, inserindo um aprofundamento na discussão sobre a caracterização física do Parque Nacional dos Campos Gerais, sua criação, quais os ecossistemas preservados e afins. O terceiro momento apresenta as questões práticas como os métodos e a discussão dos dados, encerrando com as considerações finais do trabalho.

\section{UNIDADES DE CONSERVAÇÃO E USO PÚBLICO}

Conforme a elaboração da Lei № 9.985 de 18 de julho de 2000 que institui o Sistema Nacional de Unidades de Conservação (SNUC), as UCs (Unidades de Conservação) são conceituadas como espaços territoriais e seus recursos ambientais de características naturais relevantes contemplam a conservação de limites definidos, sob regime especial de administração, ao qual se aplicam garantias adequadas de proteção (ZARATTINI; LUCENA, 2009).

Geograficamente, áreas protegidas representam todos os espaços territoriais de um país, terrestres ou marinhos, que apresentam dinâmicas de produção específica (ocupação e uso, sobretudo) e gozam de estatuto legal e regime de administração diferenciados. (MEDEIROS; SAVI; BRITO, 2005). De acordo com a (IUCN) International Union for Conservation of Nature (2018), áreas protegidas são espaços geográficos definidos, reconhecidos e geridos por meios legais com a finalidade de conservação do ambiente. Portanto, a (IUCN) classifica os parques nacionais como essenciais para a conservação da biodiversidade e para a subsistência das pessoas, especialmente em escala local.

O decreto de criação de uma UC corrobora apenas como um dos passos para a proteção destas áreas. Araújo (2012) salienta a necessidade de lapidar a gestão ou o 
manejo dessas unidades para que possam efetivar o compromisso para a qual foram criadas. Deste modo, o SNUC regulamenta as UCs em categorias, que se dividem em dois grupos, com características específicas: Unidades de Proteção Integral e Unidades de Uso Sustentável. O quadro 1 representa as categorias de UCs previstas pelo SNUC.

Quadro 1 - Quadro Consolidado das Unidades de Conservação do Brasil em 2019

\begin{tabular}{|l|l|}
\hline Unidades de Proteção Integral & Unidades de Uso Sustentável \\
\hline Estação Ecológica & Área de Proteção Ambiental \\
\hline Reserva Biológica & Área de Relevante Interesse Ecológico \\
\hline Parque Nacional & Florestas Nacionais \\
\hline Monumento Natural & Reserva Extrativista \\
\hline Refúgio da Vida Silvestre & Reserva de Fauna \\
\hline & Reserva de Desenvolvimento Sustentável \\
\hline & Reserva Particular do Patrimônio Natural \\
\hline Total: 761 & Total: 1615 \\
\hline
\end{tabular}

Fonte: Brasil (2019).

Segundo a Lei no 9.985/2000 (BRASIL, 2000) as Unidades de Conservação de Proteção Integral são compostas pelas categorias: Estação Ecológica (E.E); Reserva Biológica (REBIO); Monumento Natural (MONA); Refúgio da Vida Silvestre (RVS) e Parque Nacional (PARNA): criadas para a preservação de ecossistemas naturais de grande relevância ecológica e beleza cênica, possibilitando a realização de pesquisas científicas e o desenvolvimento de atividades de educação e interpretação ambiental, de recreação em contato com a natureza e de turismo ecológico.

As áreas de usos sustentáveis se concentram na exploração do ambiente de maneira a garantir a perenidade dos recursos ambientais renováveis e dos processos ecológicos, mantendo a biodiversidade e os demais atributos, de forma socialmente justa e economicamente viável (OLIVEIRA, 2012).

Diante disso, as UCs devem atuar não somente na preservação dos recursos naturais, mas também como locais de aprendizagem e sensibilização de pessoas a respeito da problemática ambiental (JACOBI; FLEURY; ROCHA, 2004).

A preservação dos ecossistemas associados à Floresta Ombrófila Mista (FOM), principal formação fitogeográfica do Sul do País, se deu com pelo menos 30 anos de atraso através da criação de UC de Proteção Integral. Contudo, os poucos remanescentes com extensão suficiente para atender aos objetivos de proteção encontravam-se inseridos em um mosaico de áreas de produção agrossilvipastoril instalados a partir da ocupação intensiva da região, com expressiva produção de commodities agrícolas. A criação das UCs previstas na Lei do SNUC, e nem todas estão regulamentadas, acaba por gerar argumentos utilizados por opositores que ocasionam uma série de conflitos (OLIVEIRA, 2012).

O Instituto Chico Mendes de Conservação da Biodiversidade (2016, p. 6), "[...] é o órgão executivo federal cuja atribuição é proteger o patrimônio natural e promover o 
desenvolvimento socioambiental nas áreas protegidas (unidades de conservação) brasileiras". Atualmente o Instituto Chico Mendes de Conservação da Biodiversidade (2019), é responsável por manejar 334 UCs federais distribuídas nos diferentes biomas brasileiros: Amazônia, Cerrado, Mata Atlântica, Caatinga, Pampa, Pantanal e Marinho-Costeiro.

As áreas protegidas atraem interesse público, levando a um fluxo anual de visitantes que investem seu dinheiro, tempo e esforço para conhecer e experimentar de perto estes locais. Alguns fatores determinam a experiência do visitante, incluindo a própria condição de recursos, o suporte logístico disponível no parque, bem como a prestação de serviço por toda a equipe da área e outros visitantes. São as experiências adquiridas que tornam os visitantes articulados e dão voz e apoio às áreas protegidas, bem como na efetivação de novas UCs (INTERNATIONAL UNION FOR CONSERVATION OF NATURE, 2018).

Portanto, a coleta de dados quantitativos em um sistema de monitoramento corrobora para o planejamento de um atrativo turístico. Quantificar essa demanda é compreender as principais necessidades que o atrativo possui, desde evitar lotações, usos indevidos e principalmente auxiliar os gestores a compreender esse espaço, garantindo que os serviços destinados aos visitantes estejam disponíveis.

Atrelado às discussões, o conceito de uso público vem associado muitas vezes ao turismo em áreas naturais no interior das UCs e os usuários dessas áreas são chamados de visitantes. O termo é imprescindível para que o visitante compreenda que está sujeito a condições e regras do local visitado, despertando certa sensação de intocabilidade (KINKER, 2002).

Considerando o termo público, ele diz respeito aos bens de uso comum incluindo as instâncias estatais de administração responsáveis pelo manejo e proteção das áreas, além das pessoas que as visitam em seus momentos de lazer. Como há necessidade de prestação de serviços aos visitantes, existe a possibilidade concreta de participação da esfera privada. Portanto, são identificados três grupos de atores diretamente envolvidos no uso público das áreas protegidas: os gestores, os visitantes e os prestadores de serviços (RODRIGUES, 2009).

Porém, a maioria dos Parques Nacionais brasileiros sofre com a falta de suporte para atendimento ao público, embora a legislação determine que os parques sejam bens de uso comum da sociedade. Portanto, devem estar aptos a receber o público e cumprir sua função.

Coletar dados sobre as visitas, as informações que envolvem as características das visitações, demanda e volume, são elementos importantes que ajudarão a traçar planos de uso público e estratégias de manejo, evitando o mau uso dessas unidades, que muitas vezes tornam-se propensas a sofrerem com impactos negativos decorrentes da falta de infraestrutura, suporte e informações sobre as suas funções. 


\section{MONITORAMENTO}

As "Diretrizes para Visitação em Unidades de Conservação" (BRASIL, 2006, p. 10) apresentam que o monitoramento e a avaliação, "Referem-se aos elementos que irão medir a eficácia da implementação da Unidade de Conservação e de seus instrumentos de planejamento, fornecendo elementos importantes para o realinhamento e redirecionamento do planejamento". Conseguinte, as "Diretrizes para Visitação em Unidades de Conservação" no subitem "Diretrizes Gerais", o item 1.7 traz a importância de "Conhecer e adotar diversas técnicas de manejo e procedimentos de monitoramento dos impactos da visitação, visando à minimização dos efeitos negativos e a maximização dos efeitos positivos" (BRASIL, 2006, p. 15).

Assim, Antongiovanni et al. (2002) colocam que o principal objetivo do monitoramento é produzir e divulgar informações que possam influenciar positivamente as políticas públicas voltadas para a defesa dos direitos coletivos, assim como a proteção e conservação do patrimônio cultural e ambiental. Portanto, o monitoramento está pautado em informar sobre os usos desejáveis, que devem ser compatíveis com a qualidade ambiental do local.

De acordo com o tema "Monitoramento de Biodiversidade e Gestão de Unidades de Conservação" o monitoramento, em geral, é apontado como algo pouco articulado, de objetivos vagos, dificultando o progresso do sistema, ressaltando a falta de suporte institucional apropriado, coordenação e fontes de financiamento para monitoramento. Ainda é colocado que, na esfera de gestão pública, o monitoramento se faz essencial em vista de que a sociedade investe recursos financeiros na aquisição e manejo de UCs, portanto, precisam saber se as estratégias estão atingindo aos objetivos. Em outras palavras, as seguintes perguntas precisam ser respondidas: As áreas protegidas estão efetivamente conservando os valores para que fossem criadas? A gestão dessas áreas está sendo efetiva, e como pode ser melhorada? Os projetos, atividades de manejo, estão atingindo seus objetivos e metas, e como podem ser melhorados? (INSTITUTO CHICO MENDES DE CONSERVAÇÃO DA BIODIVERSIDADE, 2015, p. 1).

O sistema de monitoramento deve evoluir em prol de novas informações, novas questões e desenvolvimento de protocolos, questões essas que possam surgir no decorrer de análises e resultados de cada método de monitoramento.

Muitas unidades ainda não dispõem de infraestrutura ou instrumentos que facilitem o monitoramento do número de visitantes, sendo verificado o uso aleatório de múltiplos métodos de aferição como: contagem direta, estimativas indiretas, registro de entradas ou de número de visitas diárias. Os exemplos de contadores são: contador automático; contagem por câmera; e contagem de ingressos. 
Burns, Popham e Gregory (2016) explicam que a West Virginia University (WVU), baseando-se no Programa Nacional de Monitoramento do Uso de Visitantes (NVUM), começou a desenvolver novos métodos para coleta de dados sobre o uso de visitantes usando câmeras em florestas nacionais nos Estados Unidos. As câmeras podem ser usadas para coletar dados referentes ao uso da trilha e ao uso de veículo. O uso de câmeras, quando comparado a outros métodos NVUM (descrever as características das visitas atividades, duração da visita, aspectos demográficos, gastos e a satisfação do visitante), pode reduzir os custos financeiros da coleta de dados em locais que registram o baixo uso de visitantes.

Alguns dos modelos de câmeras encontrados para esse tipo de atividade são: Reconyx, Bushnell Trophy Cam, Trail Cameras, Game Cameras, Primos Truth Cam, e Wildgame Innovations (EBAY, 2018), entre outras. Todas elas são desenvolvidas para captar imagens da vida selvagem, mas também podem ser ajustadas para trabalhar com monitoramento e contagem do número de visitantes em áreas protegidas.

Na Reserva Natural de Berlengas, as câmeras vêm sendo bastante usadas. No total são seis câmeras RAW Nikon Coolpix S32 (30 mm), que foram programadas em modo de captura Time Lapse, com intervalos de tempo de cinco minutos. As imagens foram analisadas através de um sistema de informação geográfica que permite a contagem e a espacialização dos utilizadores.

Outro exemplo é o estudo realizado em Zurique, na Suíça, especificamente em Uetliberg, onde o ciclismo de montanha e os múltiplos usos de trilha estavam gerando conflitos entre pedestre e ciclista. O monitoramento da trilha se deu em duas etapas, a primeira com a aplicação de 201 questionários, e na segunda foram instaladas câmeras automáticas que registraram atividades nas trilhas (WYTTENBACH; RUPF, 2014).

O monitoramento com câmera vem crescendo em algumas UCs, outro exemplo em que são usadas as câmeras para monitoramento é em parques nacionais da Áustria, para identificar as atividades dos usuários. Para evitar o vandalismo e o roubo dos dispositivos, as câmeras foram instaladas de maneira discreta em caixas de ninho de madeira (montagem em árvores) ou em uma caixa à prova de umidade (montagem em um poste de luz). As câmeras e suas respectivas caixas tiveram que ser posicionadas de modo que a mudança de cartão de memória e baterias pudesse ser feita o mais rápido possível e sem alterar o ajuste do ângulo de disparo e da posição da câmera (CZACHS; BRANDENBURG, 2014).

Além disso, as câmeras podem fornecer dados mais ricos e confiáveis do que outros equipamentos de monitoramento de uso de visitantes (por exemplo, contadores de estradas de infravermelhos ou pneumáticos). O uso de câmeras também pode reduzir os riscos à segurança humana, associados ao tempo de deslocamento e ao tempo gasto sozinho em 
áreas remotas em florestas (MONITORING AND MANAGEMENT OF VISITORS IN RECREATIONAL AND PROTECTED AREAS, 2014).

\title{
PARQUE NACIONAL DOS CAMPOS GERAIS: ÁREA DAS FURNAS GÊMEAS
}

O órgão gestor do Parque Nacional dos Campos Gerais é o Instituto Chico Mendes de Conservação da Biodiversidade, o parque está dentro dos municípios de Ponta Grossa, Castro e Carambeí (no estado do Paraná), e a maior porcentagem territorial do parque está no município de Ponta Grossa, com aproximadamente $65 \%$ da área, enquanto Castro e Carambeí complementam o total com $27 \%$ e $8 \%$, respectivamente.

O PNCG está situado na borda da Escarpa Devoniana, na zona de transição do Primeiro para o Segundo Planalto Paranaense. No Primeiro Planalto, a leste, abriga áreas florestais e a oeste, no Segundo Planalto, abriga remanescentes campestres. O parque está delimitado pelas coordenadas UTM 7210000 e 7240000 de latitude sul; e 590000 e 615000 de longitude oeste (ALMEIDA; MORO, 2007).

Desde sua criação, o PNCG vem passando por processos que estão dificultando a sua regularização fundiária. Oliveira (2012) cita que um dos principais fatores que levaram à contestação da criação do Parque Nacional dos Campos Gerais foi o fato da área ser uma extensa área de potencial produtivo agrossilvipastoris. Outro ponto mencionado pelo autor é que,

\begin{abstract}
Dentre tais usos, destacam-se cultivos anuais de grãos, com utilização de agroquímicos diversos, manutenção de florestas exóticas de eucaliptos e pinus, este último com alto potencial para a contaminação de áreas de campos naturais com proliferação espontânea de plântulas, uso público desordenado (balneários, montanhismo, moto-trails, camping, etc.) caça, pesca, entre outros (OLIVEIRA, 2012, p. 10).
\end{abstract}

Pelo fato da Floresta Ombrófila Mista (FOM) ter sido de grande importância para o processo de ocupação humana na região sul do país e todo seu valor econômico atrelado, a mata com araucária foi explorada intensivamente por madeireiras, havendo perdas através do desmatamento e da substituição de sua vegetação original por pastagens e reflorestamento com espécies exóticas (pinus), o que provocou grande redução da vegetação dessa região (MEDEIROS; SAVI; BRITO, 2005).

Referente a isso, o interesse do Ministério do Meio Ambiente em preservar estes remanescentes foi destacado no documento da Avaliação e Ações Prioritárias para a Conservação da Biodiversidade da Mata Atlântica e Campos Sulinos (BRASIL, 2000). É importante destacar também a condição geológica, uma vez que a área está localizada no 
ressalto topográfico do arenito Furnas, submetido há milhares de anos a processos erosivos que originaram as formas atuais do relevo.

Segundo o Instituto Chico Mendes de Conservação da Biodiversidade (2019), há sete áreas de atrativos utilizados como áreas de uso público no PNCG, sendo elas: Buraco do Padre; Setor Escalada Macarrão, localizado na mesma propriedade onde situa-se o Buraco do Padre; Capão da Onça; Furnas Gêmeas e Furna Grande; Ponte do Rio São Jorge; Cachoeira do Rio São Jorge; e Cachoeira da Mariquinha.

A figura 1 apresenta os sete atrativos turísticos presentes no interior do Parque Nacional dos Campos Gerais, com destaque para a Cachoeira da Mariquinha, área do estudo realizado por Garcia (2015). As Furnas Gêmeas localizam-se entre os dois polígonos representados no mapa.

Figura 1 - Mapa de localização dos atrativos no interior do Parque Nacional dos Campos Gerais - PR

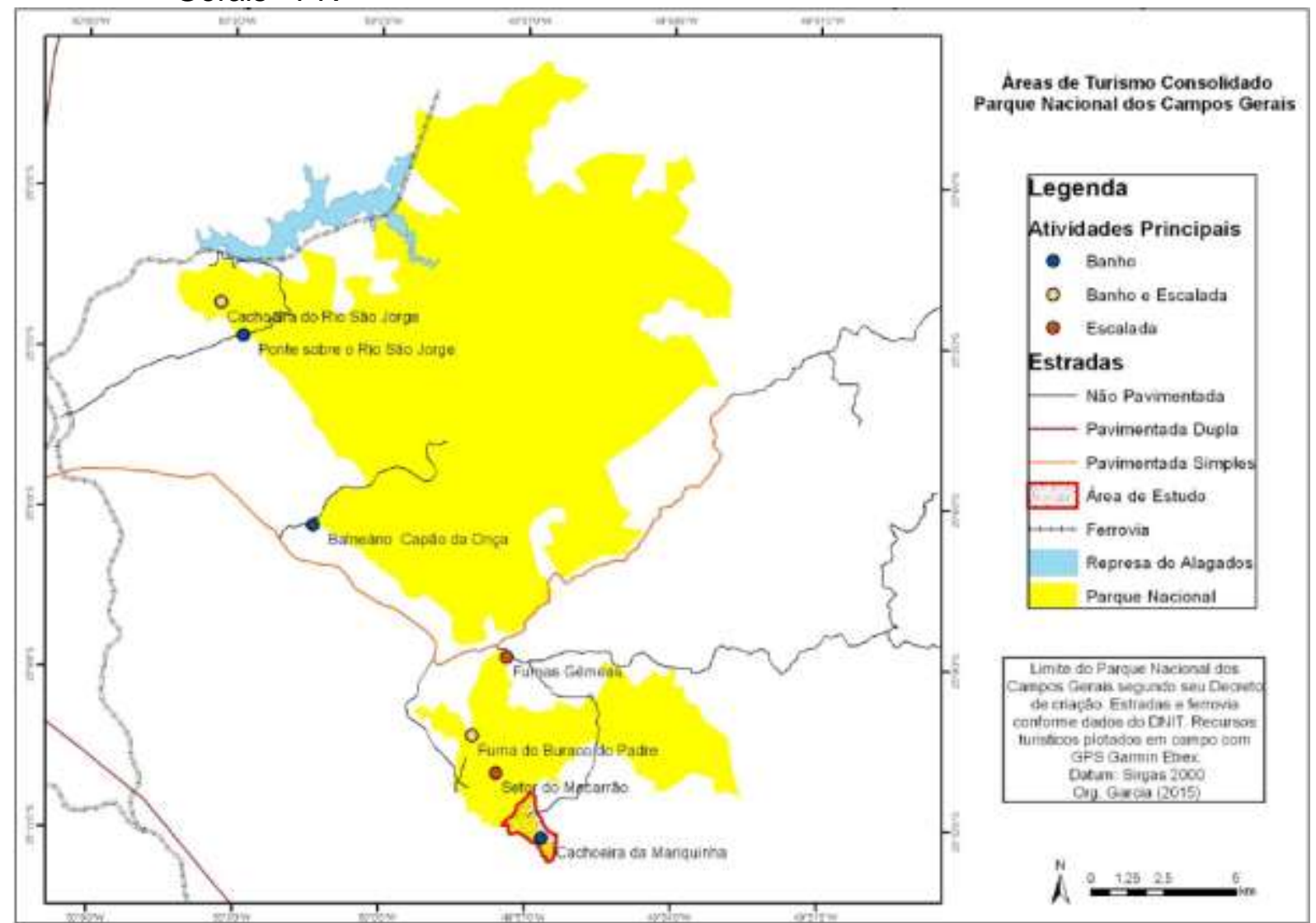

Fonte: Garcia (2015).

Dentre as atividades realizadas na UC estão a contemplação, trilhas guiadas e autoguiadas, escaladas, rapel, mountain bike, cachoeirismo, atividades de educação ambiental, visita aos balneários e vista dos mirantes naturais, dentre outras. Atualmente para ter acesso aos atrativos do parque é cobrado um valor na entrada, cada proprietário (ou administrador) cobra um valor variando de $R \$ 5,00$ a $R \$ 30,00$, dependendo do uso que 
será feito (visita ou acampamento). Como ainda não há plano de manejo, o uso público não é regulamentado. $O$ valor é revertido em benfeitorias como manutenção de trilhas, coleta de lixo, lanchonetes e campings, conforme o interesse de cada proprietário. As áreas do parque ainda são de domínio privado; a ausência de verba para fins de indenização acaba por inviabilizar a desapropriação.

Em Ponta Grossa, as furnas da região apresentam diversos fatores que vão influenciar na sua gênese. As Furnas Gêmeas, objeto de estudo, e a Furna Grande, são desenvolvidas em arenitos da Formação Furnas do Grupo Paraná, ressaltando toda beleza cênica, palco de estudos geológicos, geomorfológicos e biológicos, de grande potencial científico e didático, considerado um dos principais roteiros espeleo-geoturístico da região (GRUPO UNIVERSITÁRIO DE PESQUISAS ESPELEOLÓGICAS, 2016).

Os Campos Gerais apresentam uma vasta variedade de depressões, em dimensões e formas, assim as furnas do Estado do Paraná talvez sejam exemplos únicos no Brasil, existindo formas similares no exterior e na floresta amazônica, na Venezuela (SOARES, 1989).

O termo furnas foi atribuído regionalmente, entretanto o mais difundido é dolinas, mais frequentes em terrenos cársticos. As Furnas Gêmeas foram descritas primeiramente por Maack (1946, 1956) e por Soares (1989). Esses autores denominaram-nas como feições de erosão subterrânea (figura 2) seguidas de abatimento do teto rochoso (poços de desabamento), e quando atingem a superfície do terreno são formados grandes buracos chegando a 110 metros de profundidade e 500 metros de diâmetro.

Figura 2 - Processo de erosão subterrânea e formação de uma furna
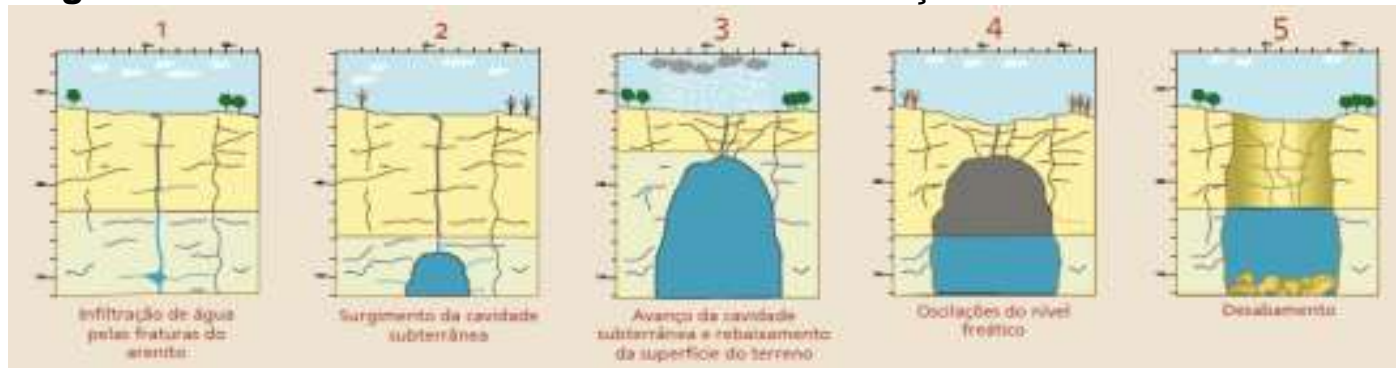

Fonte: Mineropar (2018).

Como mostra a figura, a infiltração da água provoca o desenvolvimento de drenagem subterrânea torrencial intensa, típicas dos arenitos da Formação Furnas Devoniano da Bacia do Paraná, havendo a dissolução de alguns de seus minerais, o que facilita a erosão subterrânea. Controlada por estruturas rúpteis (falhas, fraturas) determinando as direções de maior fluxo de água subterrânea, são observadas nas áreas de afloramento da Formação Furnas no Estado do Paraná (MELO, 2002). 
As Furnas Gêmeas e a Furna Grande; são atrativos do Parque Nacional dos Campos Gerais, distante 20 quilômetros do centro da cidade de Ponta Grossa (PREFEITURA MUNICIPAL DE PONTA GROSSA, 2018). As trilhas são delimitadas ao redor das furnas, sendo autoguiadas ou trilhas realizadas com guias, como as coordenadas pelo Refúgio das Curucacas. Possuem diferentes circuitos e níveis de dificuldades, desde leve à pesada (REFÚGIO DAS CURUCACAS, 2018).

As duas Furnas foram denominadas como Passo do Pupo 1 e Passo do Pupo 2 (figura 3), devido a sua localização próxima ao distrito de mesmo nome, Passo do Pupo. As características morfológicas e métricas das Furnas Gêmeas podem ser encontradas em Soares (1989). A Furna do Passo do Pupo 1 é descrita por Soares (1989, p. 15),

\begin{abstract}
Situa-se em posição topográfica elevada em relação à localidade de Passo do Pupo, podendo ser identificada de longe, desde que se conheça sua localização. Seu fundo apresenta densa vegetação. Essa furna está separada da furna número 2 por pequena faixa de terra com $17 \mathrm{~m}$ de largura. A ponte que separa as duas furnas mostra nitidamente a linha de falha do rio Quebra-Perna, com os bancos horizontais de arenito recurvados do lado ocidental pela flexão de arrasto da falha. Diâmetro: $80 \mathrm{~m}$ e $100 \mathrm{~m}$, profundidade: $50 \mathrm{~m}$.
\end{abstract}

Já a Furna do Passo do Pupo 2 é descrita por Soares (1989, p. 15) como:

Quase ligada a furna 1, sua tendência é de coalescência rápida, como aconteceu com duas furnas de Vila Velha. Possui densa vegetação no fundo, porém pequena trilha permite descer até sua base, onde subsiste ambiente de mata, sombreado e úmido. Diâmetro: $60 \mathrm{~m}$ e $100 \mathrm{~m}$, profundidade: $53 \mathrm{~m}$.

Figura 3 - Vista área das Furnas Gêmeas, denominadas Passo do Pupo 1 e 2, na localidade de Passo do Pupo - PR

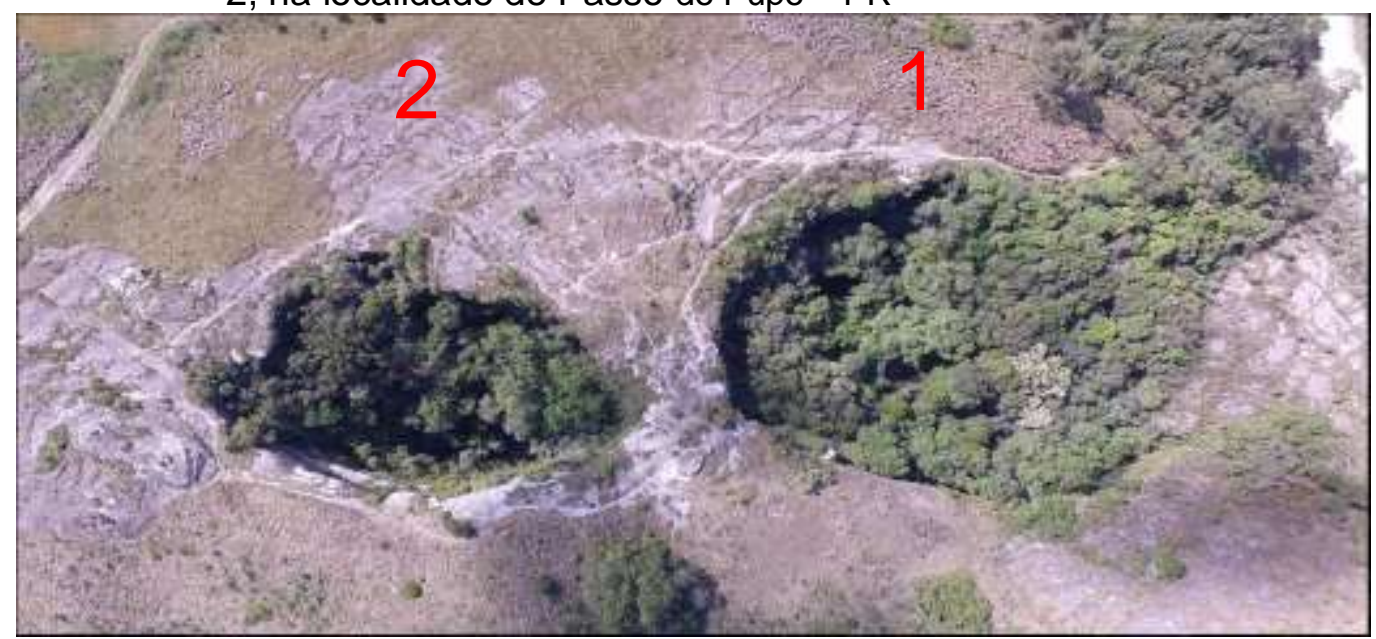

Fonte: Grupo Universitário de Pesquisas Espeleológicas (2016).

Em abril de 2018 a entrada no local passou a ser cobrada, no valor de $R \$ 5,00$. A trilha originalmente conhecida foi fechada. Anteriormente, a visitação ocorria livremente por 
visitantes e moradores da comunidade próxima, podendo ser frequentado em quaisquer horários, fazendo diferentes usos, como fogueiras, pichação em rochas e acúmulo de lixo. A antiga trilha (figura 4) mesmo sem manutenção era considerada uma trilha fácil e curta.

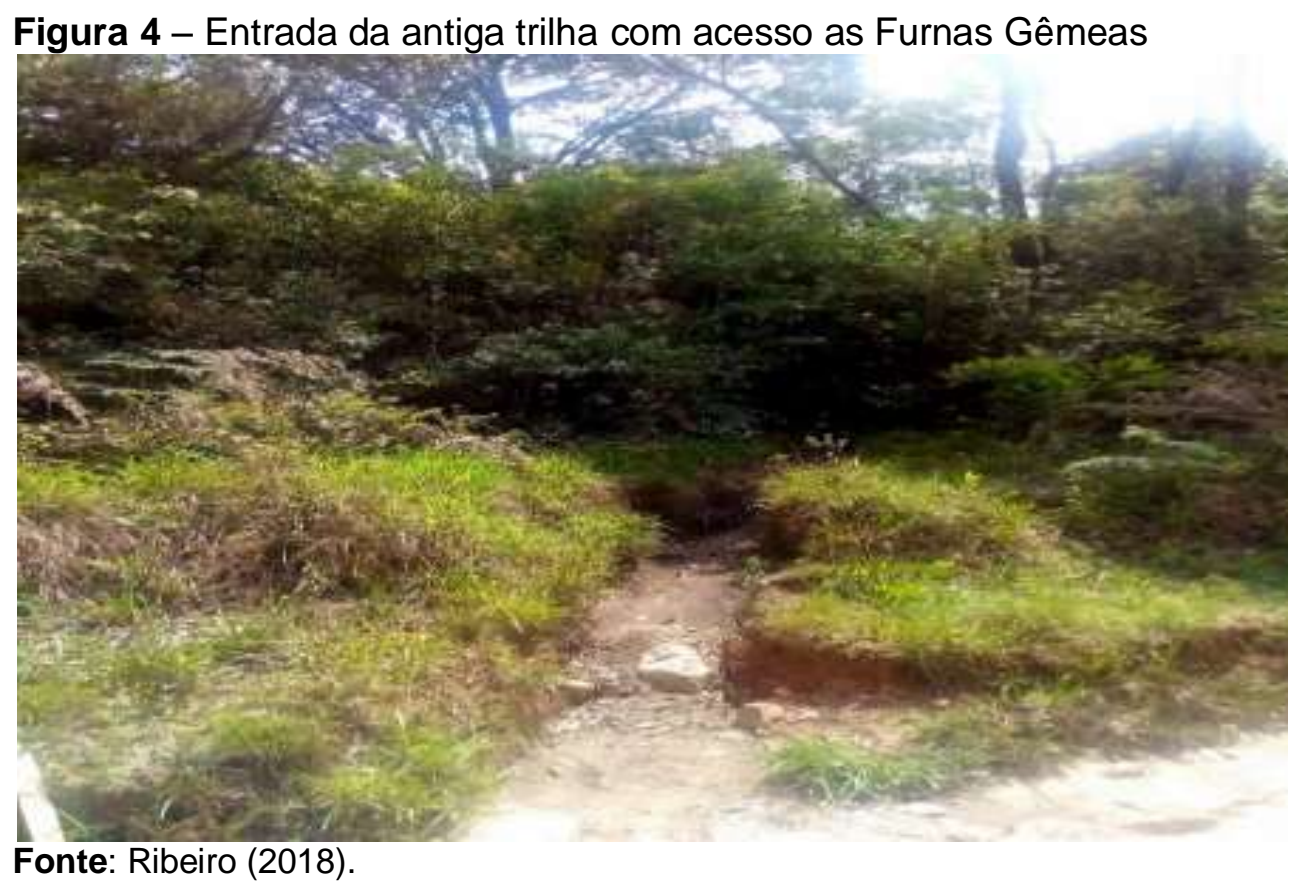

A trilha inicial (figura 5) foi totalmente fechada pelo arrendatário da área, com estacas de madeira, arames farpados, fitas sinalizadoras, e troncos de árvores, sem aviso ou explicação para aqueles que chegavam até o local.

Após o fechamento, uma nova trilha foi aberta, e a caminhada é realizada pelo meio do campo de soja, totalizando 1.100 metros (figura 6). O intuito foi deixar a trilha mais próxima ao local de cobrança do ingresso, realizado na lanchonete Dolinas Lanches. O acesso ao atrativo se dá pela Rodovia do Talco, logo após o vilarejo do Passo do Pupo. O local, entretanto, ainda não dispõe de infraestrutura para atender os visitantes, não há uma trilha demarcada, sinalização ou painéis interpretativos. 
Figura 5 - Antiga trilha fechada com arames e fitas sinalizadoras/Furnas Gêmeas

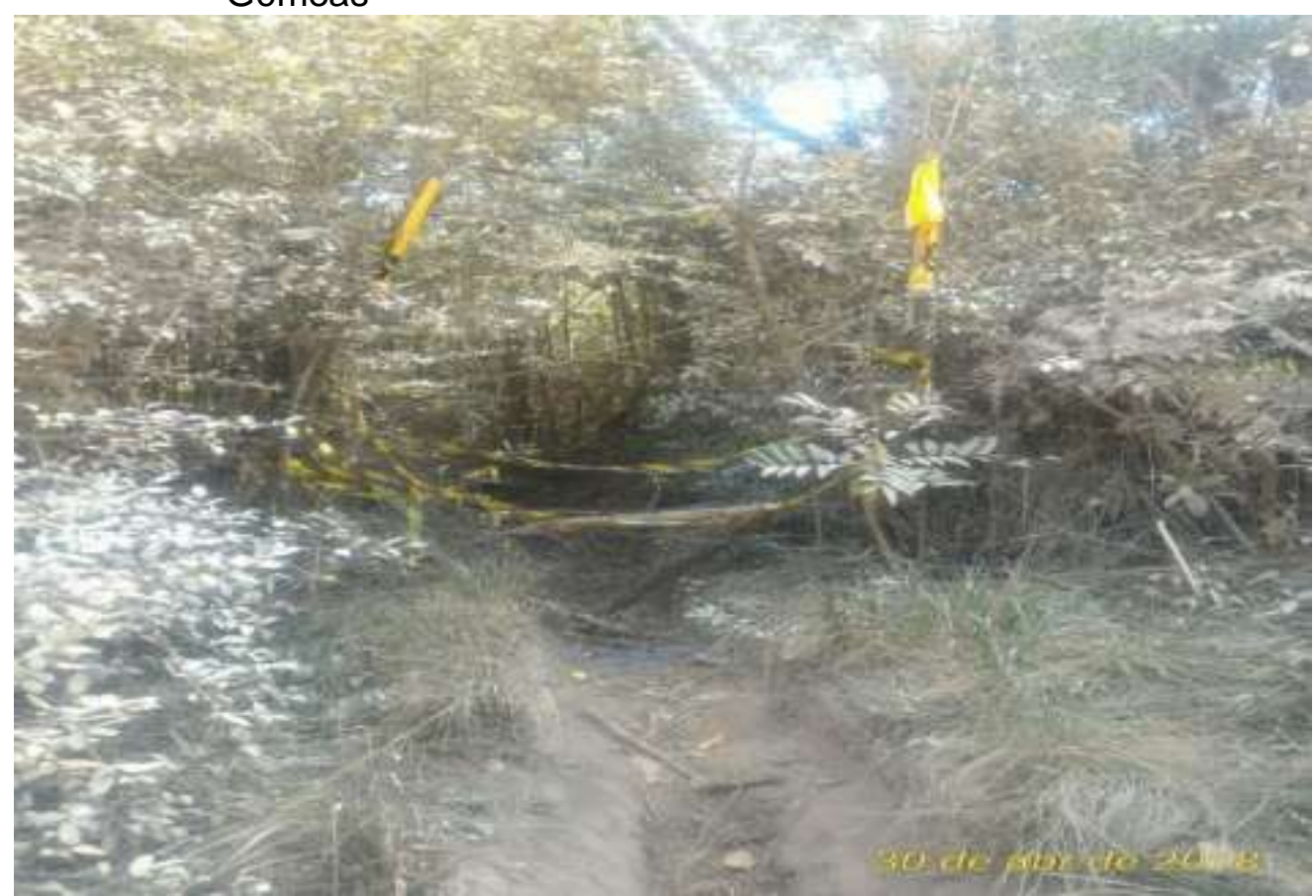

Fonte: Ribeiro (2018).

Figura 6 - Nova trilha para as Furnas Gêmeas através do campo de soja

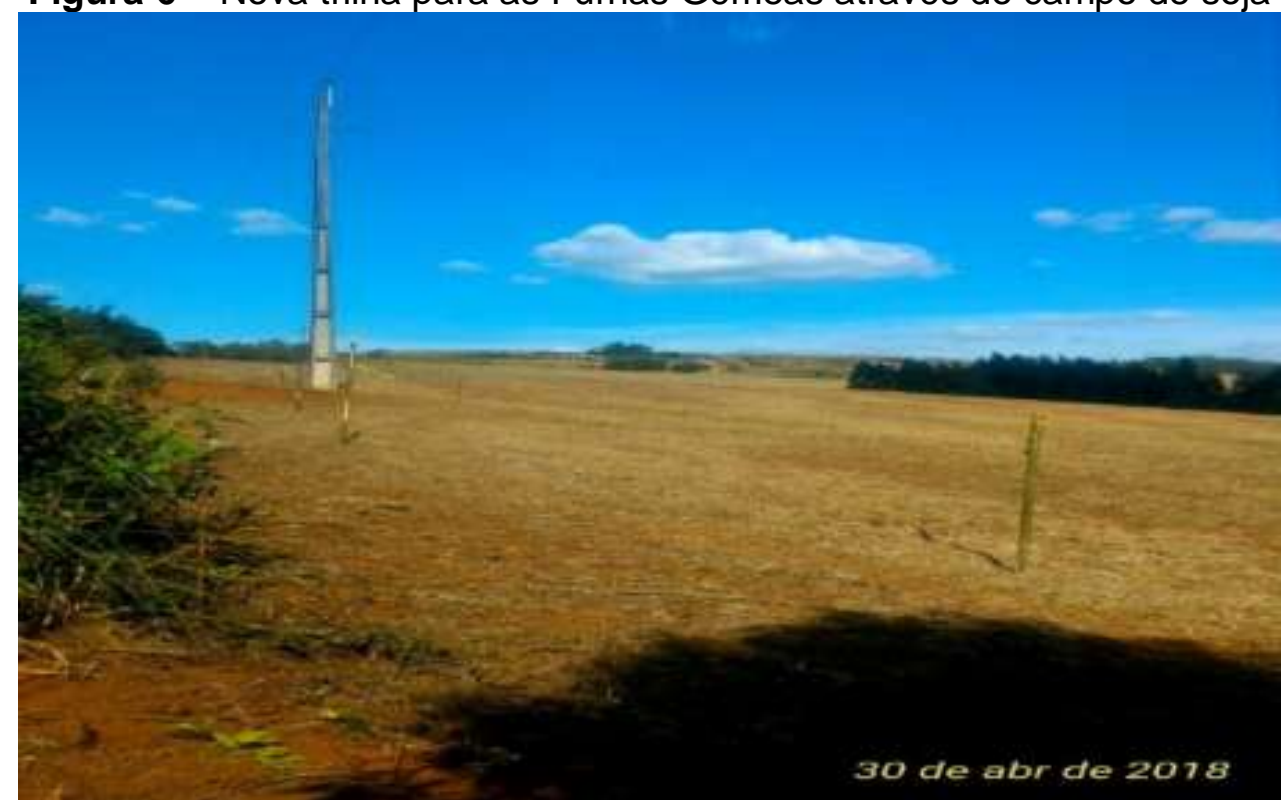

Fonte: Ribeiro (2018).

\section{MÉTODOS}

Por meio desta pesquisa foi realizado o monitoramento do número de visitantes através do uso de câmera (Game Câmera). Foram analisados os visitantes que entravam na trilha e transeuntes próximos à trilha. Esse tipo de câmera é usado fora do Brasil como ferramenta para monitoramento da fauna, principalmente de veados. A metodologia foi 
baseada na coleta de imagens com a Game Câmera, testada na Floresta Nacional Tapajós em 2014 (BURNS; POPHAM; GREGORY, 2016).

A presente pesquisa foi realizada em parceria com a West Virginia University (EUA), que forneceu a câmera para o monitoramento da trilha. A coleta totalizou cinco meses e 21 dias de registros fotográficos, com início em 09 de novembro de 2017 e finalização em 30 de abril de 2018, quando a trilha foi fechada.

Em um primeiro momento foi feito o reconhecimento da área, identificando possíveis pontos de fixação e um local do qual a câmera não ficasse aparente, por questões de segurança. Posteriormente foram realizados testes já com a câmera em locais pré-definidos, juntamente com o (ICMBio).

As configurações iniciais de captura foram definidas em intervalos de três minutos, iniciando às $06 \mathrm{~h}$ da manhã, finalizando às $23 \mathrm{~h}$ (horário de verão). Contudo, a partir das $20 \mathrm{~h}$, quando anoitecia, já não era possível visualizar a trilha, perdendo-se em média 200 fotos.

A câmera Plotwatcher Pro foi selecionada devido à qualidade de imagem, durabilidade, duração da bateria, design discreto, capacidade de armazenamento de dados, custo e facilidade de uso (para configuração e análise de dados). Em se tratando de uma lente grande-angular, a amplitude da cena capturada é maior. Este modelo usa fotografia com lapso de tempo com configurações que permitem a captura de imagens em intervalos de: um segundo, dois segundos, três segundos, cinco segundos, dez segundos, 20 segundos, 30 segundos, um minuto, três minutos, cinco minutos, dez minutos, 20 minutos, 30 minutos e 60 minutos. Deve-se levar em conta alguns fatores, como o fato de que a captura de imagens num curto intervalo exige mais memória de armazenamento e tempo no processo de análise de dados.

Após o término do horário de verão, a câmera foi programada para registrar as imagens a partir das $06 \mathrm{~h}$ até às $19 \mathrm{~h}$. Com relação aos intervalos de tempo de captura foi percebido que em um segundo foi obtida uma melhor qualidade nos resultados, identificando em alguns casos o momento em que os visitantes entravam e saiam da trilha, podendo verificar o tempo médio que permaneciam no atrativo.

A câmera foi instalada em uma árvore, cujo tronco era de angulação média, posicionada do outro lado da rua, ficando de frente para a trilha que dá acesso ao atrativo, camuflada por folhagens e outras árvores em volta e a frente (figura 7).

O posicionamento ficou a aproximadamente 1,90 metros do chão, próximo a um terreno irregular com desníveis de difícil acesso. No entanto, em certos momentos do dia por conta das árvores, o alto índice dos raios solares prejudicava a qualidade da foto. A câmera não possui infravermelho o que impossibilita fazer fotos a noite, sendo os dados coletados somente durante os períodos da manhã e tarde. 
Figura 7 - Fixação da câmara Plotwatcher Pro

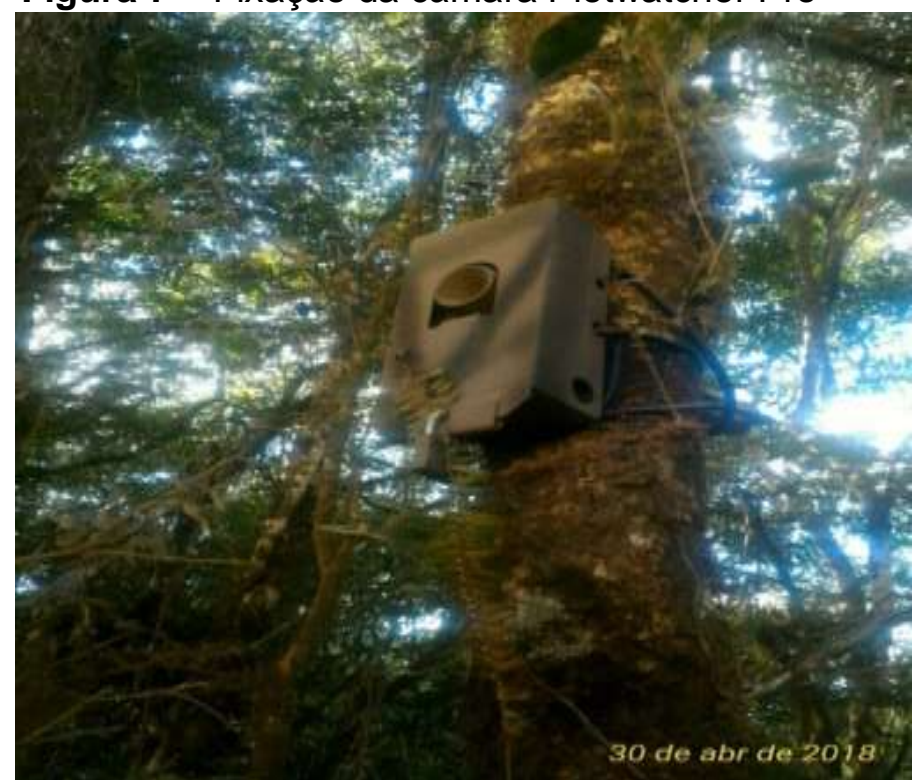

Fonte: Ribeiro (2018).

\section{RESULTADOS}

Ao analisar os dados, um total de 168.389 imagens, foram identificados quantos visitantes foram até o atrativo nesses cinco meses e 21 dias de coleta. A figura 8 exibe 0 total de visitantes em cada mês, chegando a um total de 683 visitantes.

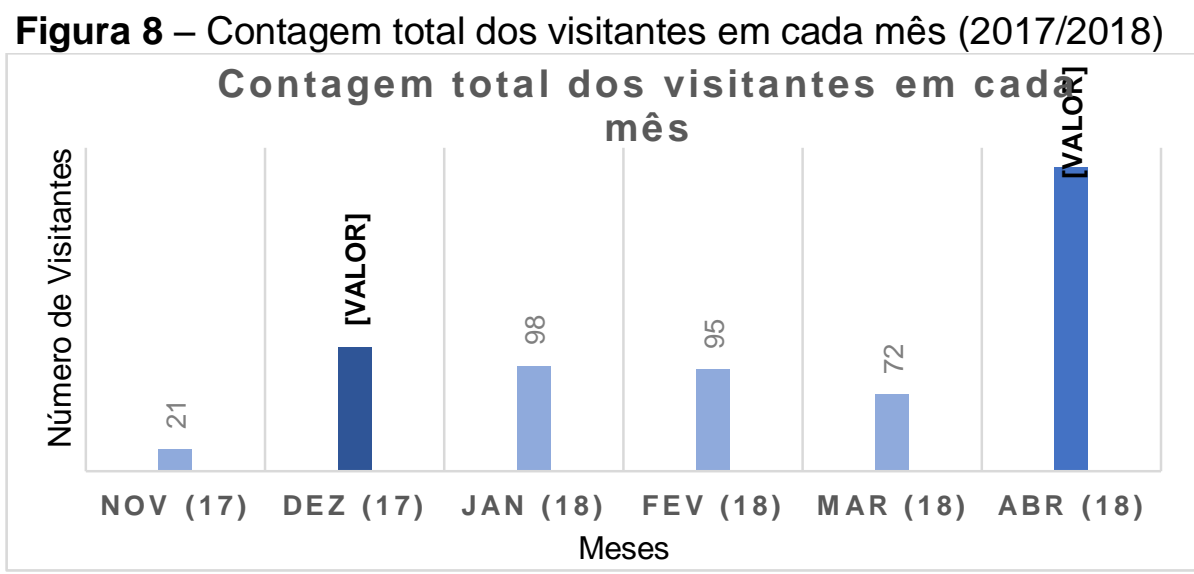

Fonte: os próprios autores.

O mês de novembro foi caracterizado pelo menor número de visitações, com 21 visitas no total. Já no mês de dezembro os registros foram maiores, sendo um dos meses que apresentou maior frequência de visitantes, com 115 no total. As visitas se concentraram mais de quinta-feira a domingo. Em janeiro e fevereiro as visitações caíram em relação a dezembro, totalizando 98 visitas no mês de janeiro e 95 no mês de fevereiro. Em março, o total foi de 72 visitantes. 
O mês de abril representa o mês com maior número de visitações. Dados do website Weather Spark (2018) mostram que as melhores épocas para visitar os atrativos de Ponta Grossa começam no início de março e vão até o meio de maio, e depois do fim de outubro até o meio de dezembro. A estação, que possui poucos dias encobertos e poucas chuvas, permanece por 4,4 meses, de 21 de novembro a $1^{\circ}$ de abril, com temperatura máxima média diária de $26^{\circ} \mathrm{C}$. Talvez em função disso o mês de abril apresentou o maior registro de visitantes, com 282 visitantes no total, e os finais de semana foram os dias que concentraram mais visitantes.

A figura 9 apresenta o total de visitas por hora referente aos meses de monitoramento. Os visitantes começam a frequentar o atrativo a partir das 07 horas, com quatro visitas registradas. A partir das 14 horas o índice passa a aumentar, com 55 visitantes, tendo picos cada vez maiores até o período das 19 horas. Entre as 19 e 20 horas, o total de visitantes foi de 36.

Figura 9 - Total de visitas por hora referente aos dados coletados

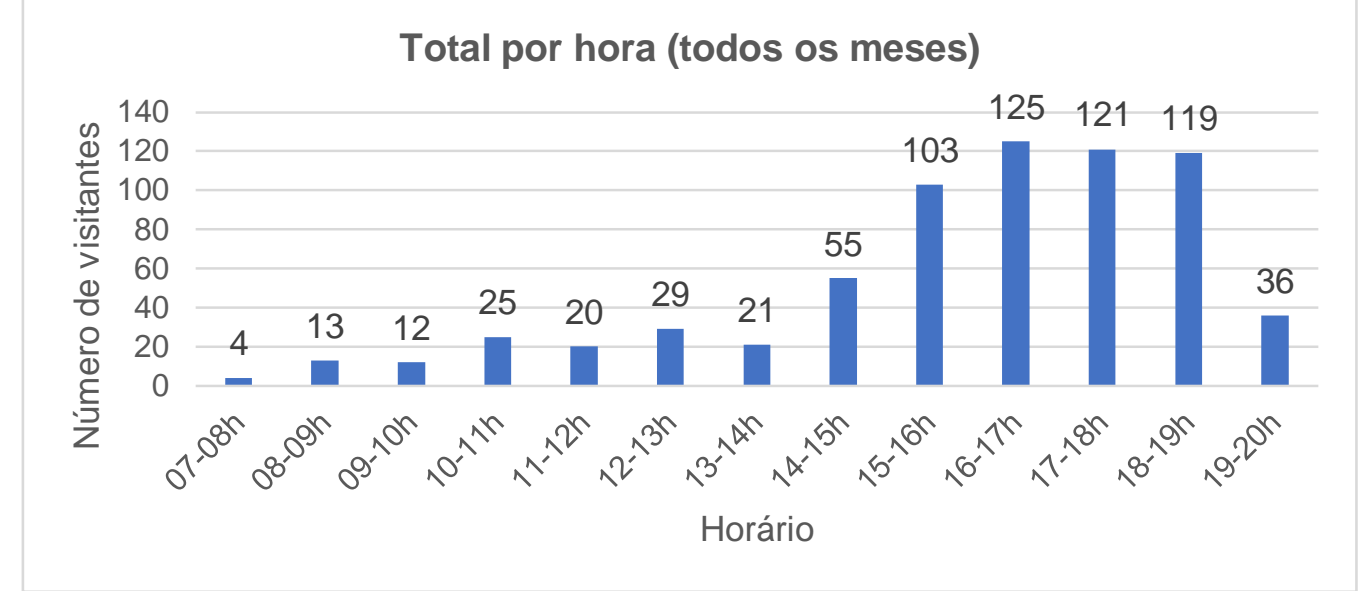

Fonte: os próprios autores.

Conforme a análise dos resultados coletados é a partir das 15 horas que o fluxo de visitas passa a aumentar, principalmente em horários próximos ao entardecer. Pode-se deduzir que um dos usos do atrativo é a contemplação da paisagem de campos naturais, das espécies de pássaros e dos mirantes naturais formados pelas rochas. Além disso, sugere-se que o pôr do sol também é algo que desperta interesse desses visitantes.

\section{CONSIDERAÇÕES FINAIS}

Esse tipo de monitoramento através de câmera foi testado pela primeira vez no Parque Nacional dos Campos Gerais, na área do atrativo Furnas Gêmeas. Como não era cobrada a entrada até o mês de abril de 2018, não havia estimativas ligadas ao número de 
visitantes. Entretanto, durante a pesquisa, observou-se o fechamento da trilha e o início da cobrança de ingressos.

Com os dados obtidos, percebe-se que as visitações ocorreram com maior frequência de quinta-feira a domingo. Observou-se que há uma preferência pelo período da tarde e o entardecer, em todos os meses, com picos de visitação a partir das 15 horas, próximo ao pôr do sol que, dependendo do mês e dia, acontecia entre as 17 e 18 horas, 18 e 19 horas ou 19 e 20 horas. Outra possibilidade é a de que a visita ocorria quando os visitantes voltavam de outro atrativo e paravam nas Furnas Gêmeas por ser um local em que o acesso era gratuito e fácil.

Dados como esse podem servir de auxílio para a elaboração do plano de manejo do local. Reforça-se a necessidade de planos de uso público que organizem a visitação dentro das UCs, proporcionando melhorias na qualidade da visita e possibilitando a minimização dos impactos gerados pela atividade turística. Em linhas simples, o manejo de impactos da visitação envolve uma série de ações técnicas e de gestão para minimizar tais impactos ao ambiente e maximizar a qualidade da experiência aos visitantes.

Os resultados visam contribuir com a gestão do PNCG, auxiliando no monitoramento dos atrativos. Ao conhecer um pouco mais sobre o comportamento dos visitantes, torna-se mais viável produzir e divulgar informações voltadas à melhoria do manejo do uso público nas unidades de conservação. Vê-se que o objetivo do monitoramento está pautado em informar sobre os usos desejáveis, que devem ser compatíveis com a qualidade ambiental do local.

\section{REFERÊNCIAS}

ALMEIDA, C. G.; MORO, R. S. Análise da cobertura florestal no Parque Nacional dos Campos Gerais, Paraná, como subsídio ao seu plano de manejo. Terr@ Plural, Ponta Grossa, PR, v. 1, n. 1, p. 115-122, jan./jul. 2007.

ANTONGIOVANNI, M.; NIGRO, C.; QUEIROLO, D. RICARDO, F. Monitoramento das Unidades de Conservação Brasileiras: uma avaliação da situação atual. In: CONGRESSO BRASILEIRO DE UNIDADES DE CONSERVAÇÃO, 3., Fortaleza, 2002. Anais [...]. Fortaleza: Fundação o Boticário de Proteção à Natureza, 2002. p. 338-347.

ARAÚJO, M. Unidades de conservação: importância e história no mundo. In: ARAÚJO, M.; MARQUES, C. P.; BITTENCOURT, R. F. (org.). Unidades de conservação no Brasil: o caminho da gestão para resultados. São Carlos: Rima, 2012. p. 37-50.

BRASIL. Avaliação e ações prioritárias para a conservação da biodiversidade da Mata Atlântica e Campos Sulinos. Brasília: MMA/SBF, 2000. Disponível em: https://docplayer.com.br/3439686-Avaliacao-e-acoes-prioritarias-para-a-conservacao-dabiodiversidade-da-mata-atlantica-e-campos-sulinos.html. Acesso em: 19 nov. 2018.

BRASIL. Decreto Federal de 23 de março de 2006. Cria o Parque Nacional dos Campos Gerais, no Estado do Paraná, e dá outras providências. Disponível em: 
http://www.planalto.gov.br/ccivil_03/_Ato2004-2006/2006/Dnn/Dnn10796.htm. Acesso em: 23 out. 2019.

BRASIL. Diretrizes para visitação em unidades de conservação. Brasília: Ministério do Meio Ambiente, 2006.

BRASIL. Lei no 9985 de julho de 2000. Regulamenta o art. 225, § 10, incisos I, II, III e VII da Constituição Federal, institui o Sistema Nacional de Unidades de Conservação da Natureza e dá outras providências. Disponível em:

http://www.planalto.gov.br/ccivil_03/LEIS/L9985.htm. Acesso em: 30 mar. 2018.

BRASIL. Ministério do Meio Ambiente. Cadastro nacional de unidades de conservação. 2019. Disponível em: https://www.mma.gov.br/images/arquivo/80229/CNUC_JUL19\%20\%20B_Cat.pdf. Acesso em: 19 set. 2019.

BURNS, R. C.; POPHAM, A.; GREGORY, M. Game camera demonstration project. Morgantown: West Virginia University, 2016.

CZACHS, C.; BRANDENBURG, C. Visitor monitoring with time lapse trail cameras. Monitoring and management of visitors in recreational and protected areas. In:

INTERNATIONAL CONFERENCE ON MONITORING AND MANAGEMENT OF VISITORS IN RECREATIONAL AND PROTECTED AREAS (MMV), 7., Tallinn, ET, 2014. Abstracts [...]. Tallinn: MMV, 2014. p. 1-4. Disponível em: http://mmv.boku.ac.at/refbase/files/2014Czachs_Visitor_monitoring_with_time_lapse_trail_cameras.pdf. Acesso em: 14 nov. 2017.

EBAY. Reconyx. Disponível em: https://www.ebay.com/bhp/reconyx. Acesso em: 22 jul. 2018.

GARCIA, L. V. M. Cachoeira da Mariquinha: impactos e potencialidades do uso público no Parque Nacional dos Campos Gerais-PR. 2015. Dissertação (Mestrado em Gestão do Território) - Universidade Estadual de Ponta Grossa, Ponta Grossa, 2015. Disponível em: http://tede2.uepg.br/jspui/handle/prefix/575. Acesso em: 23 out. 2019.

GRUPO UNIVERSITÁRIO DE PESQUISAS ESPELEOLÓGICAS - GUPE. 2016. Disponível em: https://www.gupe.org.br/. Acesso em 28 nov. 2017.

INSTITUTO CHICO MENDES DE CONSERVAÇÃO DA BIODIVERSIDADE (ICMBio). Boas práticas na gestão de áreas protegidas no Brasil. In: PRADO, F.; SILVA, C. H.;

CAMARGOS, M. C.; MELOF, P. E. C. (ed.). Boas práticas na gestão de Unidades de

Conservação. Brasília: IPE; ICMBio, 2016. p. 6. Disponível em:

http://www.icmbio.gov.br/portal/images/stories/comunicacao/publicacoes/revista_boas_pratic a_2016.pd. Acesso em: 23 out. 2019.

INSTITUTO CHICO MENDES DE CONSERVAÇÃO DA BIODIVERSIDADE (ICMBio). Unidades de Conservação. Disponível em:

http://www.icmbio.gov.br/portal/unidadesdeconservacao/biomas-brasileiros. Acesso em: 13 abr. 2019.

INSTITUTO CHICO MENDES DE CONSERVAÇÃO DA BIODIVERSIDADE. Monitoramento de biodiversidade e gestão de unidades de conservação. Biodiversidade Brasileira:

Revista Eletrônica, Brasília, 2015. Disponível em:

http://www.icmbio.gov.br/portal/images/stories/o-que-

fazemos/pesquisas/bio_brasil_convite_envio_artigos.pdf. Acesso em: 23 out. 2019.

INTERNATIONAL UNION FOR CONSERVATION OF NATURE - IUCN. What is a protected area? Disponível em:

http://www.iucn.org/about/work/programmes/gpap_home/pas_gpap/. Acesso em: 06 abr. 2018.

JACOBI, C. M.; FLEURY, L. C.; ROCHA, A. C. Percepção ambiental em unidades de conservação: experiência com diferentes grupos etários no parque estadual da Serra do Rola Moça, MG. In: ENCONTRO DE EXTENSÃO DA UFMG, 7., 2004, Belo Horizonte. 
Anais [...]. Belo Horizonte: UFMG, 2004. p. 1-7. Disponível em: https://www.ufmg.br/congrext/Meio/Meio12.pdf. Acesso em: 05 ago. 2018.

KINKER, S. Ecoturismo e conservação da natureza em Parques Nacionais. São Paulo: Papirus, 2002.

MAACK, R. Fenômenos carstiformes de natureza climática e estrutural de arenitos do Estado do Paraná. Arquivos de Biologia e Tecnologia, Curitiba, v. 11, p. 151-162, 1956.

MAACK, R. Geologia e geografia da região de Vila Velha e considerações sobre a glaciação carbonífera do Brasil. Arquivos do Museu Paranaense, Curitiba, v. 5, p. $102-200,1946$.

MEDEIROS, J. de D.; SAVI, M.; BRITO, B. F. A. Seleção de área para criação de Unidades de Conservação na Floresta Ombrófila Mista. Biotemas, Florianópolis, SC, v. 18, n. 2, p. 3350 , set. 2005 .

MELO, M. S. Lagoa Dourada, PR - Furna assoreada do Parque Estadual de Vila Velha. In: SCHOBBENHAUS, C.; CAMPOS, D. A.; QUEIROZ, E. T.; WINGE, M.; BERBERT-BORN, M. L. C. (ed.). Sítios geológicos e paleontológicos do Brasil. Brasília: DNPM-CPRM-SIGEP, 2002. p. 289-298.

MINEROPAR. Minerais do Paraná. Furnas do Parque Estadual de Vila Velha. Disponível em:

http://www.mineropar.pr.gov.br/arquivos/File/Paineis_geologicos/FurnasdoParqueEstaduald eVilaVelha_portugues.pdf. Acesso em: 5 ago. 2018.

MONITORING AND MANAGEMENT OF VISITORS IN RECREATIONAL AND PROTECTED AREAS - MMV. 2014. Disponível em: http://mmv.boku.ac.at/. Acesso em: 22 jul. 2018.

OLIVEIRA, E. A. de. O Parque Nacional dos Campos Gerais: processo de criação, caracterização ambiental e proposta de priorização de áreas para regularização fundiária. 2012. Tese (Doutorado em Engenharia Florestal) - Universidade Federal do Paraná, Curitiba, 2012.

PARANÁ. Justiça Federal. Ação ordinária (procedimento comum ordinário) no 5023730 35.2012.404.7000/PR. Disponível em: https://www.jfpr.jus.br/gedpro/verifica/verifica.php. Acesso em: 23 out. 2019. código verificador 6871219v8.

PREFEITURA MUNICIPAL DE PONTA GROSSA. Atrativos turísticos. Disponível em: http://www.pontagrossa.pr.gov.br/turismo. Acesso em: 20 abr. 2018.

REFÚGIO DAS CURUCACAS. Trilhas Ecológicas. Disponível em:

https://refugiodascurucacas.com.br/trekking. Acesso em: 27 ago. 2018.

RODRIGUES, C. O. 0 uso do público nos parques nacionais: a relação entre as esferas pública e privada na apropriação da biodiversidade. 2009. Tese (Doutorado em Desenvolvimento Sustentável) - Centro de Desenvolvimento Sustentável, Universidade de Brasília, Brasília, DF, 2009.

SOARES, O. Furnas dos Campos Gerais, Paraná. Curitiba: Scientia et Labor: Editora da UFPR, 1989. (Série Didática).

WEATHER SPARK. Condições meteorológicas médias de Ponta Grossa. Disponível em: https://pt.weatherspark.com/y/29814/Clima-caracter\%C3\%ADstico-em-Ponta-Grossa-Brasildurante-o-ano\#Sections-BestTime. Acesso em: 27 dez. 2018.

WYTTENBACH, M.; RUPF, R. Urban mountain biking: multiple-uses of trails on the Uetliberg in Zurich, Switzerland. Monitoring and Management of Visitors in Recreational and Protected Areas. p. 1-5. In: INTERNATIONAL CONFERENCE ON MONITORING AND MANAGEMENT OF VISITORS IN RECREATIONAL AND PROTECTED AREAS (MMV), 7., Tallinn, ET, 2014. Abstracts [...]. Tallinn: MMV, 2014. p. 320. Disponível em: http://mmv.boku.ac.at/refbase/files/2014-Wyttenbach_Urban_mountain_biking.pdf. Acesso em: 14 nov. 2017. 
O Uso da "Game Câmera" como Ferramenta para Monitoramento da Visitação nas Furnas Gêmeas...

ZARATTINI, A. C.; LUCENA, E. M. P. de. Sistema nacional de unidades de conservação. Brasília, DF: ICMBio, 2009. Disponível em:

http://www.icmbio.gov.br/portal/images/stories/comunicacao/legislacaoambientalvolume1.pdf . Acesso em: 10 ago. 2017.

Recebido: maio de 2019.

Aceito: outubro de 2019. 